\title{
Increased searching and handling effort in tall swards lead to a Type IV functional response in small grazing herbivores
}

\author{
Nicol Heuermann • Frank van Langevelde • \\ Sipke E. van Wieren · Herbert H. T. Prins
}

Received: 9 December 2009/Accepted: 21 December 2010/Published online: 11 January 2011

(C) The Author(s) 2011. This article is published with open access at Springerlink.com

\begin{abstract}
Understanding the functional response of species is important in comprehending the species' population dynamics and the functioning of multi-species assemblages. A Type II functional response, where instantaneous intake rate increases asymptotically with sward biomass, is thought to be common in grazers. However, at tall, dense swards, food intake might decline due to mechanical limitations or if animals selectively forage on the most nutritious parts of a sward, leading to a Type IV functional response, especially for smaller herbivores. We tested the predictions that bite mass, cropping time, swallowing time and searching time increase, and bite rate decreases with increasing grass biomass for different-sized Canada geese (Branta canadensis) foraging on grass swards. Bite mass indeed showed an increasing asymptotic relationship with grass biomass. At high biomass, difficulties in handling long leaves and in locating bites were responsible for increasing cropping, swallowing, and searching times. Constant bite mass and decreasing bite rate caused the intake rate to decrease at high sward biomass after reaching an optimum, leading to a Type IV functional response. Grazer body mass affected maximum bite mass and intake rate, but did not change the shape of the functional response. As grass nutrient contents are usually highest in short swards, this Type IV functional response in geese leads to an intake rate that is maximised in these swards. The lower grass biomass at which intake rate was
\end{abstract}

Communicated by Douglas Robinson.

N. Heuermann $(\bowtie) \cdot$ F. van Langevelde

S. E. van Wieren - H. H. T. Prins

Resource Ecology Group, Wageningen University,

Droevendaalsesteeg 3a, 6708 PB Wageningen, The Netherlands

e-mail: Nicol.Heuermann@yahoo.com maximised allows resource partitioning between differentsized grazers. We argue that this Type IV functional response is of more importance than previously thought.

Keywords Body mass - Branta canadensis - Geese . Intake rate $\cdot$ Bite mass

\section{Introduction}

Consumer-resource interactions largely depend on the rate and selectivity of food intake of the consumers (Prins and van Langevelde 2008). The relationship between food intake rate and the availability of food items is described by the functional response (Solomon 1949; Holling 1959; Spalinger and Hobbs 1992). The shape of this functional response has been subject to numerous investigations, modelling exercises and discussions following the work of Holling (1959). Functional and aggregative response curves, the latter describing the change in population density in response to resource availability, are crucial for predicting the distribution and population dynamics of species by providing a link between different trophic levels (Sutherland 1996). Moreover, differences in the shape of the functional response of different-sized grazers might determine whether competition or facilitation between species prevails and thereby affect assemblage composition (Prins and Olff 1998; van Langevelde et al. 2008). A proper understanding of factors that shape the functional response of species is thus of crucial importance in comprehending both population dynamics and functioning of multi-species assemblages.

For grazing herbivores, the instantaneous intake rate has been found to increase asymptotically with grass biomass or grass height as a Type II functional response (Black and 
Kenney 1984; Gross et al. 1993; Wilmshurst et al. 1999a). Forage quality decreases with increasing grass height and age, as fibre content increases and nutrient concentrations decrease (Collins 1988; Ombadi et al. 2001). This negative relationship between grass biomass and forage quality forces many grazers to trade-off forage quality with intake rate, with the highest nutrient and energy intake at intermediate sward biomass (Fryxell 1991; Fryxell et al. 2004; van de Koppel et al. 1996; van der Wal et al. 1998; Wilmshurst et al. 1999a, b) leading to a dome-shaped relationship between grass biomass and nutrient or energy intake. For small herbivores like geese, there are indications that the functional response does not only decrease in terms of nutrient/energy intake but already on dry matter basis (van der Wal et al. 1998; Lang and Black 2001; Durant et al. 2003; Bos et al. 2004). It is argued that this decreased intake rate at high grass biomass is typical for small herbivores, because they should select a diet of high quality (Bell 1971; Jarman 1974) and they will more easily be impaired in walking and handling in tall swards, while larger herbivores would exhibit a Type II functional response. In a study of food intake of several Anatidae, Durant et al. (2003) indeed found this functional response type, called Type IV, only for the smallest species in their study, the wigeon (Anas penelope L.). However, a Type IV functional response has also been observed for large mammalian grazers foraging on complex swards (Bergman et al. 2000; Drescher et al. 2006; Benvenutti et al. 2006). This Type IV functional response is furthermore found for bacteria living on a substrate that is toxic at high concentrations (Andrews 1968; van Gemerden 1974), and for predators foraging on prey that form swarms at high densities (Welty 1934; Mori and Chant 1966; Jeschke and Tollrian 2005). A Type IV functional response, even though not regarded as likely by Spalinger and Hobbs (1992) to describe foraging, may thus be of more importance than previously thought.

Whereas the processes determining the Type II functional response are extensively investigated, insight in the underlying determinants of the Type IV functional response remains elusive (van Langevelde et al. 2008). Durant et al. (2003) attributed the decrease in intake rate to an increase in cropping time as sward height rose. Swallowing time, on the other hand, was assumed to be a linear increasing function of bite mass, and therefore asymptotically increasing with sward height. However, the separate effects of cropping and swallowing time were not measured during their study. We think that a decreasing bite rate in their study could have resulted from an increase in swallowing time, cropping time or searching time or a combination of these. While an increase in searching time would indicate an increased time necessary to select bites (Bergman et al. 2000), an increase in cropping or swallowing time would reflect mechanical limitations imposed by the sward structure and bite composition. Another cause of decreased instantaneous intake rate at high biomass could be a decrease in bite mass for the same reasons, namely either mechanical limitations or a volitional reduction of bite mass to increase the nutritional quality of the forage taken. Such a reduction out of choice takes special significance in understanding browsing, as Wilson and Kerley (2003) argued that these herbivores generally crop smaller bites than they are able to, due to a trade-off between instantaneous dry matter intake rate and nutrient intake.

Our aim was first to analyse the shape of the functional response, studying a large range of grass biomass, large enough to expect a Type IV functional response, and second to unravel the determinants of the functional response. We tested the predictions that bite mass, cropping time, swallowing time and searching time increase, and bite rate decreases with increasing grass biomass. To determine the effect of body mass on the shape of the functional response, we selected different-sized subspecies of the Canada goose Branta canadensis L. The Canada goose is a unique species because it encompasses 11 subspecies which differ considerably in body mass. Despite their large size differences, all subspecies are very similar in morphology and ecology, being specialised grazers like all other species of the genus Branta. This is an important difference from the study of Durant et al. (2003), where geese and ducks with different feeding styles were compared.

\section{Materials and methods}

\section{Animals}

The 17 geese that took part in this study were grouped in three body mass classes further referred to as small [six individuals of the subspecies Branta c. minima (Ridgway) and one of the subspecies B. c. leucopareia (Brandt), with an average weight of $1.6 \mathrm{~kg}$ with an average bill length of $25.6 \mathrm{~mm}$ ), medium-sized (four individuals of the subspecies $B$. canadensis occidentalis (Baird), weighing on average $3.0 \mathrm{~kg}$, bill length on average $38.0 \mathrm{~mm}$ ] and large [six individuals which were hybrids of the subspecies $B$. $c$. canadensis (Linnaeus), B. c. maxima (Delacour) and B. c. moffiti (Aldrich), on average $4.6 \mathrm{~kg}$ and $54.3 \mathrm{~mm}$ bill length]. All individuals were bred in captivity and were at least 2 years old. The geese were weighed to the nearest $0.01 \mathrm{~kg}$ every 6 weeks. The smaller subspecies, $B . \quad c$. minima and B. c. leucopareia, are considered to be a separate species (Branta hutchinsii Richardson) by some authors (Banks et al. 2004). 
The study animals were kept in a stable throughout the experimental period. Water for drinking and bathing and grain were available ad libitum, and on days without trials the geese received fresh vegetables. All trials were conducted between March and July 2003 in Wageningen, the Netherlands. Before the onset of the experiment, all animals were slowly accustomed to the experimental procedure during a period of 5 weeks, first in small groups of two to six animals and later individually. The experiment was approved by Wageningen University's commission for the use of animals in experimental trials (DEC register code 2003032.b).

\section{Methods}

For each trial, one animal was led to an extra pen $(2 \mathrm{~m} \times 6 \mathrm{~m})$ in close proximity to the rest of the geese. A turf of perennial ryegrass (Lolium perenne L.) var. cancan $(21 \mathrm{~cm} \times 35 \mathrm{~cm}$ in a seed tray of $5 \mathrm{~cm}$ height) grown in a greenhouse was placed in the experimental pen while an equal turf was kept outside the pen as control. During each trial, the behaviour of the goose was videotaped for analysis. The trial was ended when the animal lost interest in foraging or when about $50 \%$ of the biomass of the turf had been removed to avoid severe depletion.

Both experimental and control turves were weighed to the nearest $0.01 \mathrm{~g}$ before and after each trial to determine the offtake by the goose and control for evapotranspiration, respectively. Plant height before the trial was determined by measuring 11 plants to the nearest $\mathrm{mm}$ (extended tiller height; sensu Delgarde et al. 2000) from the ground to the top of the longest leaf while it was stretched. The lengths of all leaves of these 11 plants were also determined. After each trial, measurements were repeated on 11 grazed plants. The remaining vegetation of each turf was clipped to ground level to determine total biomass. The clippings of the control turf were air-dried to determine the ratio between fresh and dry mass. For the calculation of bulk density grass biomass $\left(\mathrm{g} \mathrm{m}^{-2}\right)$ was divided by plant height (m).

Biomass of the turfs was determined individually, resulting in a continuum of sward heights and biomass. Biomass varied between 1 and $470 \mathrm{~g} \mathrm{~m}^{-2}$ and the height of the grass plants varied between 3 and $36 \mathrm{~cm}$. For every goose, there were $8-16$ trials over the whole range of biomass measures. Because of the lower number of individuals of the intermediate body mass class, the number of trials per individual was elevated in this body mass class (16-22).

Videotapes (25 frames $s^{-1}$ ) of all trials were analysed frame by frame to determine the number of bites taken from the turf. Foraging time was defined as time actively foraging excluding scanning, preening, and other behaviours.
It consisted of cropping time $T_{\text {crop }}$ (from the closing of the bill around plant material until the complete severing of this material), swallowing time $T_{\text {swallow }}$ (swallowing of the bites cropped; geese do not chew) and swallow-free searching time $T_{\text {search }}$, which did not include the search for new bites while swallowing the last bite and which will be referred to as searching time. This searching was defined as visual inspection of the turf and movement of the bill toward a piece of grass until the bill was opened to grasp the vegetation, when cropping started. New bites could be cropped before the earlier ones were completely swallowed, but swallowing was suspended during cropping. Handling time is the sum of the cropping time and swallowing time. By considering swallow-free searching time only, the three processes searching, cropping, and swallowing do not overlap in time.

Searching, cropping, and swallowing time for all bites (s) were summed separately and then divided by the number of bites to derive the mean searching, cropping, and swallowing time per bite. The same was done for handling and total foraging time (s). Instantaneous intake rate IIR ( $\mathrm{g} \mathrm{s}^{-1}$ ) was calculated by dividing the weight loss of the turf minus evapotranspiration loss by total foraging time on the turf. Bite mass ( $\mathrm{g}$ ) was determined by dividing the weight loss minus evapotranspiration by the number of bites taken from the turf. The number of bites divided by the foraging time gave the bite rate. Results for bite mass and intake rates are expressed as gram dry mass. Trials with $<10$ bites ( 8 out of 274 trials) were excluded from the analysis because weight loss due to evapotranspiration exceeded the amount of weight removed by foraging.

\section{Statistical analysis}

Using regression we tested which model, Type II or Type IV, could best describe the hypothesized relationships between the determinants of the functional response and grass biomass. To describe the Type II functional response the Michaelis-Menten equation was chosen:

$\mathrm{IIR}=\frac{a \times \text { biomass }}{b+\text { biomass }}$

where $a$ is the maximum intake rate $(\mathrm{g} / \mathrm{s})$ and $b$ is the grass biomass $\left(\mathrm{g} \mathrm{m}^{-2}\right)$, at which intake rate reaches half of its maximum ( $b$ affects the steepness of the increase of the first part of the curve). We used the Monod-Haldane equation (Andrews 1968; Gentleman et al. 2003) to describe the Type IV functional response:

$\mathrm{IIR}=\frac{a \times \text { biomass }}{b+\text { biomass }+c \times \text { biomass }^{2}}$

where $a\left(\mathrm{~g} \mathrm{~s}^{-1}\right)$ determines the highest intake rate and $b$ $\left(\mathrm{g} \mathrm{m}^{-2}\right)$ affects mainly the steepness of the increase of the 
first part of the curve and the position of the optimum. An increase in $b$ results in a lower optimum that is reached at higher biomass values. Increasing $c\left(\mathrm{~m}^{2} \mathrm{~g}^{-1}\right)$ decreases the maximum intake rate, which is reached at lower biomass values and leads to a steeper decline in the second part of the curve. The highest intake rate is reached at a biomass of $\sqrt{\frac{b}{c}}$. For comparison, we also included the Spalinger and Hobbs (1992) process 3 equation that relates intake rate to bite mass with

$\mathrm{IIR}=\frac{R_{\max } \times S}{h+S}$

with $S=$ bite mass and $h=$ cropping time.

The Monod-Haldane function equals the Type II model if $c=0$; for $c>0$, it shows a downward curve after the optimum is reached, and for $c<0$, the curvature is upwards. The Monod-Haldane function is commonly applied in microbial growth studies, where the substrate is limiting at low concentrations and inhibitory at high concentrations. Equations 1, 2 and 3 were fitted separately for all three body mass classes to determine whether the size classes showed different responses to tall vegetation. Because this was not the case, the three body mass classes were analysed together and the effect of body mass $(M)$ on the functional response was tested by including body mass effects on the different parameters, e.g.,

$\mathrm{IIR}=\frac{a \times M \times \text { biomass }}{b+\text { biomass }+c \times \text { biomass }^{2}}$

or

$\mathrm{IIR}=\frac{a \times \text { biomass }}{b \times M+\text { biomass }+c \times \text { biomass }^{2}}$

It was examined whether parameter estimates for $a, b$, and $c$ scaled with body mass in an isometric or allometric fashion by incorporating a scaling $d$ exponent as:

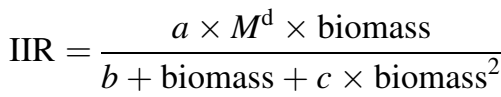

While the inclusion of body mass as independent variable is expected to account for some variation between individuals, we also included individuals as random intercept effect, and models with and without individual effects were compared using the $F$ test. We also looked at random individual effects on the parameters for the best supported models. Random individual effects were tested by adding a dummy variable for each (but one) individual:

$\mathrm{IIR}=\frac{a \times \text { biomass }}{b+\text { biomass }+c \times \text { biomass }^{2}}+\varepsilon_{i}$

Separate regressions were fitted for all determinants of the functional response (bite mass, searching time, cropping time, and swallowing time) with grass biomass and body mass as independent variables. We tested whether the dependent variable was independently or linearly related to grass biomass using general linear models. The Michaelis-Menten equation and GLM regression with ln-transformed independent variables were used to model increases and decreases toward an asymptote, respectively. To provide insight in the role of bite mass and other plant characteristics grass biomass was replaced by bite mass, plant height, bulk density and the average number of leaves per plant in alternative models; these characteristics were all positively related to grass biomass.

The different models for each dependent variable were compared using Akaike's information criterion (AIC) (Burnham and Anderson 2002), which was calculated as $\mathrm{AIC}=N \times \ln \frac{\text { resSS }}{N}+2 k$, where $N$ is the number of observations, $k$ the number of parameters in the regression model plus one and resSS is the residual sum of squares of the ordinary least squares model. The likelihood of each model within the set of alternatives was estimated using Akaike weights. Parameter estimation was done using ordinary least squares instead of a maximum likelihood approach as they give the same results when maximum likelihood estimation is based on a normal distribution (Burnham and Anderson 2002). As our residuals did not deviate from a normal distribution the ordinary least squares approach has the advantage of providing significance estimates based on $F$ statistics. The nested model structure of the two competing models (Eqs. 1 and 2) was selected to allow the use of the $F$ test for comparison. The $F$ test (residual sum of squares reduction test) was used to determine whether the addition of body mass as an independent variable significantly improved the model fit.

\section{Results}

Intake rate

The Type IV functional response fitted significantly better for the small and the large body mass class compared with the Type II functional response. For the intermediate body mass class, both curves were quite similar and the Type was not significantly different from the Type IV model (Table 1). The Spalinger and Hobbs process 3 functional response model showed higher $R^{2}$ than the other two models, showing a high influence of bite mass on intake rate. As the Type IV model was able to describe the functional response of all three body mass classes, we combined them and added body mass as continuous variable (like in Eqs. 4, 5 and 6; Table 2). All models 
containing a body mass effect on the parameter $a$ in the Type IV functional response model (Eq. 4) performed well, whereas models without body mass effect on $a$ were not able to well explain the observations (Fig. 1). The model with the highest Akaike weight included a scaling exponent of 0.89 for the effect of body mass on the parameter $a$ (Table 2). The second best model had an effect of body mass on $a$ without scaling exponent (Akaike weight $=0.27, R^{2}=0.62$ ) and the third best model contained both a body mass effect on $a$ and $b$ (without scaling exponents, Akaike weight $=0.23, R^{2}=0.62$ ).

Bite mass

Grass biomass and body mass were the most important factors determining bite mass. Bite mass was well described by any asymptotic model with grass biomass as independent variable $\left(R^{2} \approx 0.72\right)$. The regression model with the highest Akaike weight included an effect of body mass on maximum bite mass with a scaling exponent of 1.28 (Fig. 2; Table 2). The second best model showed an isometric effect of body mass on the parameter $a$ (Akaike weight $=0.003, R^{2}=0.71$ ). Using other plant characteristic did not improve the fit.

\section{Bite rate}

Bite rate decreased in an asymptotic fashion with grass biomass as captured by an logarithmic function with body mass as additional variable (Table 2; Fig. 3a). The second best model also included an interaction between body mass and grass biomass (Akaike weight $=0.30, R^{2}=0.39$ ). However, bite mass in combination with a logarithmic function of grass height was a much better predictor of bite rate (Table 3 ).

Searching, cropping and swallowing time

The average duration of swallow-free searches increased with increasing grass biomass as predicted A linear model with grass biomass and body mass as independent variable, including an interaction between body mass and biomass described searching time much better than any other model (Table 2; Fig. 3b). Inclusion of other predictors showed that a simple linear relationship with bite mass described searching time as well as the former model (Table 3). Cropping time was best described by a linear model with grass biomass (Table 2; Fig. 3c). The second best model for cropping time also included body mass as additional variable (Akaike weight $=0.23, R^{2}=0.48$ ). Grass height was an even better predictor of cropping time (Table 3 ). Swallowing time was linearly related to grass biomass, the by far most likely model included body mass as independent variable and an interaction between body mass and grass biomass (Table 2; Fig. 3d). Replacing grass biomass by bite mass improved the model fit and even better was a combination of bite mass and plant height as predictor of swallowing time (Table 3; Fig. 4).

\section{Plant characteristics}

We first checked how the plant characteristics were related to grass biomass. Plant height on the turfs was asymptotically related to grass biomass, reaching a maximum of about $30 \mathrm{~cm}$ (with leaves extended) at $200 \mathrm{~g} \mathrm{~m}^{-2}$ (Table 3). The number of leaves per plant also increased asymptotically

Table 1 Comparison between the Type II (Michaelis-Menten) and Type IV (Monod-Haldane function) functional response model in relation to grass biomass (bio) for three different body mass classes in Canada geese Branta canadensis separately

\begin{tabular}{|c|c|c|c|c|c|c|c|}
\hline $\begin{array}{l}\text { Body mass } \\
\text { class }\end{array}$ & Model & Regression equation & $n$ & $R^{2}$ & $F$ & $F$ test & $P$ value \\
\hline Small & Type II & $\frac{0.006 \times \text { bio }}{4.84+\text { bio }}$ & 95 & 0.16 & 9.13 & & \\
\hline Small & Type IV & $\frac{0.025 \times \text { bio }}{53.76+\text { bio }+0.026 \times \text { bio }^{2}}$ & 95 & 0.29 & 12.33 & 15.83 & $<0.001$ \\
\hline Small & SpaHo & $\frac{0.012 \times S}{0.005+S}$ & 95 & 0.52 & 51.16 & & \\
\hline Medium-size & Type II & $\frac{0.013 \times \text { bio }}{14.74+\text { bio }}$ & 74 & 0.43 & 26.62 & & \\
\hline Medium-size & Type IV & $\frac{0.015 \times \text { bio }}{18.28+\text { bio }+0.0007 \times \text { bio }^{2}}$ & 74 & 0.43 & 17.93 & 0.74 & 0.392 \\
\hline Medium-size & SpaHo & $\frac{0.020 \times S}{0.012+S}$ & 74 & 0.57 & 46.82 & & \\
\hline Large & Type II & $\frac{0.021 \times \text { bio }}{13.83+\text { bio }}$ & 92 & 0.39 & 28.57 & & \\
\hline Large & Type IV & $\frac{0.077 \times \text { bio }}{101.48+\text { bio }+0.016 \times \text { bio }^{2}}$ & 92 & 0.49 & 28.40 & 17.56 & $<0.001$ \\
\hline Large & SpaHo & $\frac{0.027 \times S}{0.012+S}$ & 92 & 0.65 & 87.89 & & \\
\hline
\end{tabular}

The $F$ test was done to determine whether the Type IV model gave a better fit than the Type II model 
Table 2 Parameter estimates and statistics for the regression models of goose intake variables against grass biomass with the highest probability

\begin{tabular}{|c|c|c|c|c|c|c|c|c|c|}
\hline Dependent & Regression & $R^{2}$ & $F_{m, n}$ & $m$ & $n$ & $\begin{array}{l}\text { Akaike } \\
\text { weight }\end{array}$ & $F$ test & $P$ value & $R^{2}$ \\
\hline Intake rate IIR $\left(\mathrm{g} \mathrm{s}^{-1}\right)$ & $\frac{0.0083+M^{0.89} \times \text { bio }}{31.70+\text { bio }+0.0047 \times \text { bio }^{2}}$ & 0.63 & 109.3 & 4 & 259 & 0.488 & 2.78 & $<0.001$ & 0.69 \\
\hline Bite mass $S\left(\mathrm{~g} \mathrm{bite}^{-1}\right)$ & $\frac{0.0067 \times M^{1.28} \times \text { bio }}{66.63+\text { bio }}$ & 0.72 & 223.4 & 3 & 260 & 0.997 & 4.52 & $<0.001$ & 0.78 \\
\hline Bite rate (bites $\mathrm{s}^{-1}$ ) & $2.377-0.278 \times \ln ($ bio $)-0.074 \times M$ & 0.38 & 89.2 & 2 & 262 & 0.693 & 1.55 & 0.084 & 0.44 \\
\hline$T_{\text {search }}\left(\mathrm{s} \mathrm{bite}^{-1}\right)$ & $0.105-0.000027 \times$ bio $+0.0046 \times M+0.000149 \times$ bio $\times M$ & 0.30 & 39.3 & 3 & 261 & 0.998 & 2.92 & $<0.001$ & 0.45 \\
\hline$T_{\text {crop }}\left(\mathrm{s} \mathrm{bite}^{-1}\right)$ & $0.072+0.00063 \times$ bio & 0.48 & 245.5 & 1 & 263 & 0.627 & 1.76 & 0.038 & 0.54 \\
\hline$T_{\text {swallow }}\left(\mathrm{s} \mathrm{bite}^{-1}\right)$ & $0.571-0.00054 \times$ bio $+0.034 \times M+0.00078 \times$ bio $\times M$ & 0.41 & 60.9 & 3 & 261 & $>0.999$ & 3.01 & $<0.001$ & 0.51 \\
\hline
\end{tabular}

$P$ values of the regressions are all lower than 0.001. Akaike weights give the likelihood of a model to be the best one compared with all alternative models in the analysis. The last three columns give the significance of random individual effects $\left(F\right.$ test, $P$ value) as well as the $R^{2}$ of the model with random individual effects

bio biomass, $M$ body mass, $T_{\text {search }}$ searching time, $T_{\text {crop }}$ cropping time, $T_{\text {swallow }}$ swallowing time

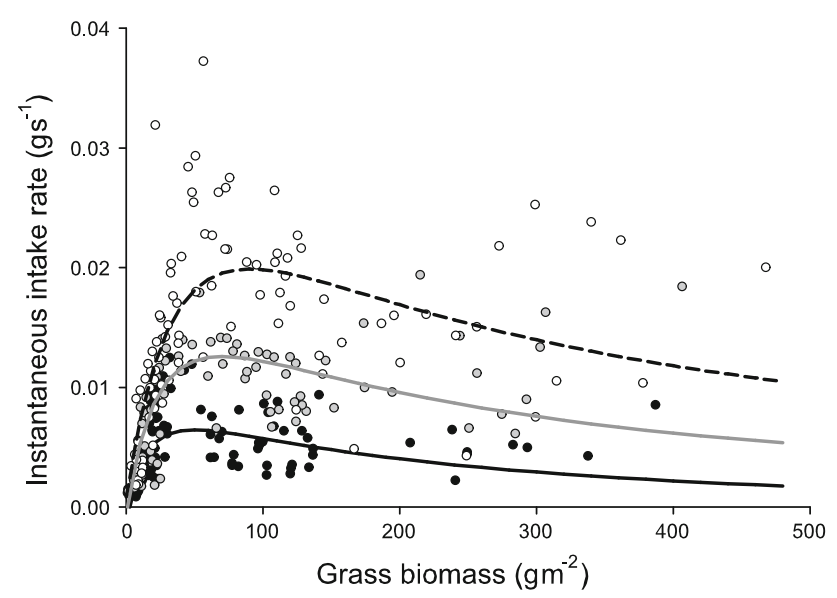

Fig. 1 Instantaneous intake rate of Canada geese Branta canadensis in relation to grass biomass and body mass for all body mass classes combined. Lines represent body mass $M=1.5 \mathrm{~kg}$ (black line), $M=3 \mathrm{~kg}$ (grey line) and $M=5 \mathrm{~kg}$ (broken line). Points represent observations for the small (black circles), intermediate (grey circles) and large (open circles) body mass class. For equation and statistics see Table 2

with biomass, and the length of the second leaf, which was the youngest fully grown leaf, was linearly related to plant height (Table 3). Intake rate was not affected by the fraction of biomass removed from a turf for the large (i.e., the slope did not differ from zero: $t_{0.025,86}=-0.16, P=0.88$ ) and intermediate body mass class $\left(t_{0.025,70}=-0.21, P=0.83\right)$, when random individual effects were included. It was slightly positively affected by the fraction of biomass removed for the small body mass class $\left(t_{0.025,88}\right)=2.36$, $P=0.02$, slope $=0.00004)$.

\section{Discussion}

In this study, we present a detailed analysis of the functional response of a small grazer, the Canada goose. This

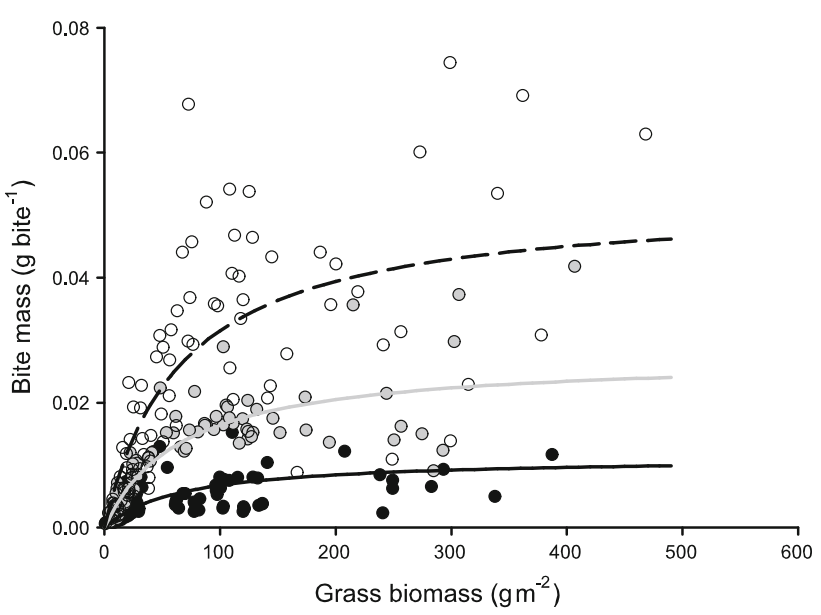

Fig. 2 The relationship between grass biomass and bite mass in Canada geese. The asymptotic model is shown for three sizes [body mass $M=1.5 \mathrm{~kg}$ (black line), $M=3 \mathrm{~kg}$ (grey line) and $M=5 \mathrm{~kg}$ (broken line)] and observations for small (black circles), intermediate (grey circles) and large (open circles) geese. For equation and statistics see Table 2

grazer allowed us to study body mass effects within one species without having to consider differences in physiology. We determined the shape of the functional response and examined the key components of the foraging process separately to determine which animal and plant characteristics led to this shape. We first discuss the effect of body mass on the functional response and then the effects of sward characteristics on the different components of intake rate and its determinants.

Body mass and functional response

We found only quantitative differences between the body mass classes, the shape of the functional response curve did not differ. Goose body mass affected the absolute value of the maximum intake rate as well as the position of the 

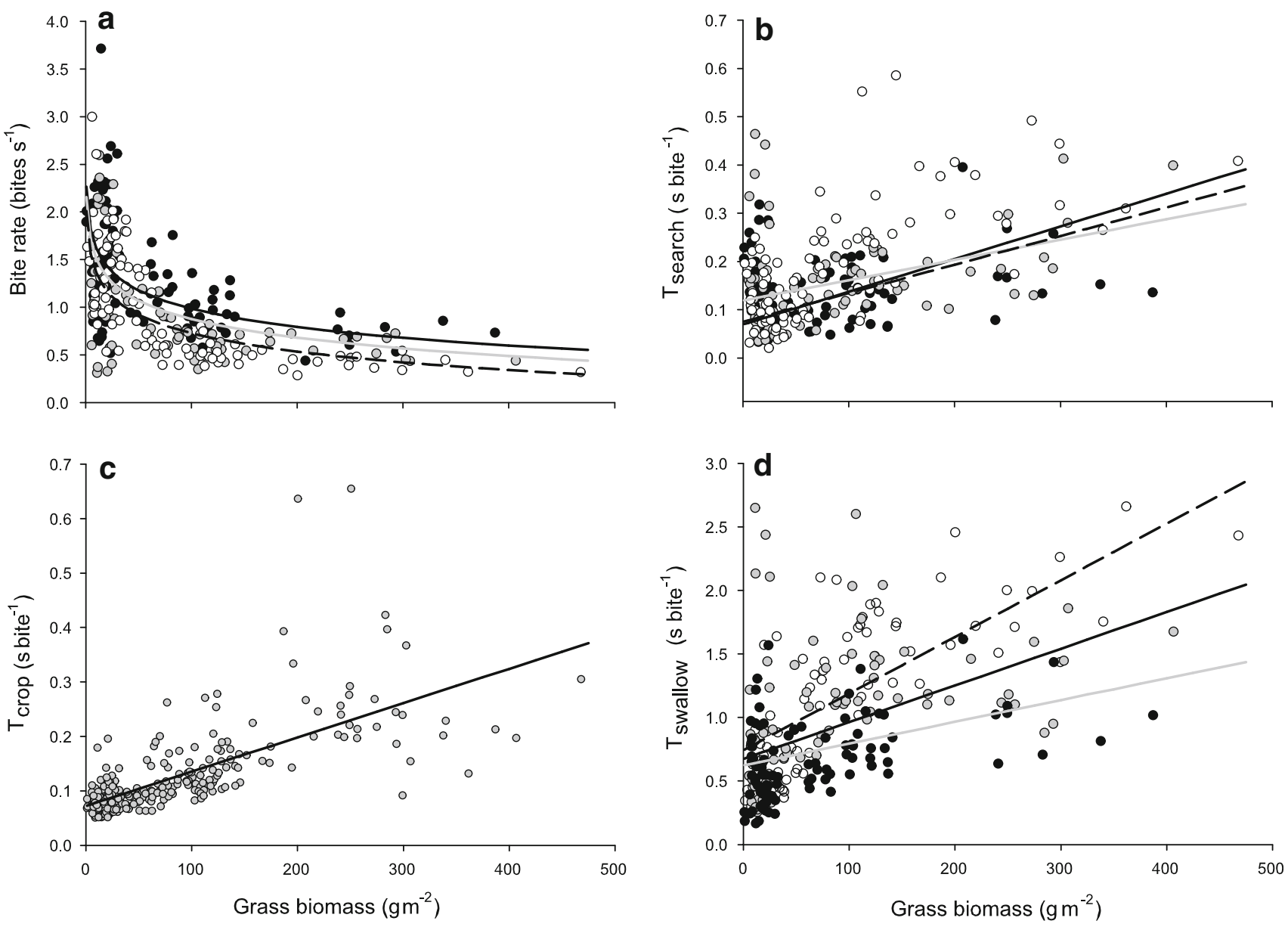

Fig. 3 Relationships between goose bite rate and its determinants and grass biomass: a bite rate, $\mathbf{b}$ searching time, $\mathbf{c}$ cropping time d swallowing time. Models with a significant effect of body mass are shown for three sizes [body mass $M=1.5 \mathrm{~kg}$ (black line), $M=3 \mathrm{~kg}$

(grey line) and $M=5 \mathrm{~kg}$ (broken line)] and observations for small (black circles), intermediate (grey circles) and large (open circles) geese. For equations and statistics see Table 2

Table 3 Parameter estimates and statistics for the regression models relating sward characteristics and goose intake variables with the highest probability

\begin{tabular}{|c|c|c|c|c|c|c|}
\hline Dependent & Regression & $R^{2}$ & $F_{m, n}$ & $m$ & $n$ & Akaike weight \\
\hline Grass height $g h(\mathrm{~cm})$ & $\frac{41.96 \times \text { bio }}{107.75+\text { bio }}$ & 0.85 & 729.72 & 2 & 262 & \\
\hline Length of the 2 nd youngest leaf $(\mathrm{cm})$ & $-4.70+0.92 g h$ & 0.97 & $5,921.95$ & 1 & 158 & \\
\hline No. of leaves & $\frac{4.84 \times \text { bio }}{70.72+\text { bio }}$ & 0.85 & 730.88 & 2 & 262 & \\
\hline Length of the 2 nd leaf removed $(\mathrm{cm})$ & $-1.75+0.48 g h+\varepsilon_{i}$ & 0.72 & 4.98 & 18 & 125 & \\
\hline$T_{\text {search }}\left(\mathrm{s} \mathrm{bite}^{-1}\right)$ & $-0.0067+0.127 \times T_{\text {swallow }}+\varepsilon_{i}$ & 0.60 & 20.17 & 3 & 4 & \\
\hline Bite mass $S$ (g bite $\left.{ }^{-1}\right)$ & No better fit than model in Table 2 & & & & & \\
\hline Bite rate (bites s ${ }^{-1}$ ) & $2.556-0.545 \times \ln (g h)-9.510 \times S$ & 0.59 & 188.5 & 2 & 261 & 0.986 \\
\hline$T_{\text {search }}\left(\mathrm{s} \mathrm{bite}^{-1}\right)$ & $0.107+3.874 \times S$ & 0.30 & 112.87 & 1 & 262 & 0.374 \\
\hline$T_{\text {crop }}\left(\mathrm{s} \mathrm{bite}^{-1}\right)$ & $0.0355+0.00606 \times g h$ & 0.45 & 263.1 & 1 & 262 & 0.616 \\
\hline$T_{\text {swallow }}\left(\right.$ s bite $\left.^{-1}\right)$ & $0.36+20.02 \times S+0.021 \times g h-5.81 \times S \times M$ & 0.60 & 200.5 & 2 & 261 & $>0.999$ \\
\hline
\end{tabular}

$P$ values of the regressions are all lower than 0.001 . Akaike weights give the likelihood of a model to be the best one compared with all alternative models in the analysis

bio biomass, $M$ body mass, $g h$ grass height, $S$ bite mass, $T_{\text {search }}$ searching time, $T_{\text {crop }}$ cropping time, $T_{\text {swallow }}$ swallowing time 


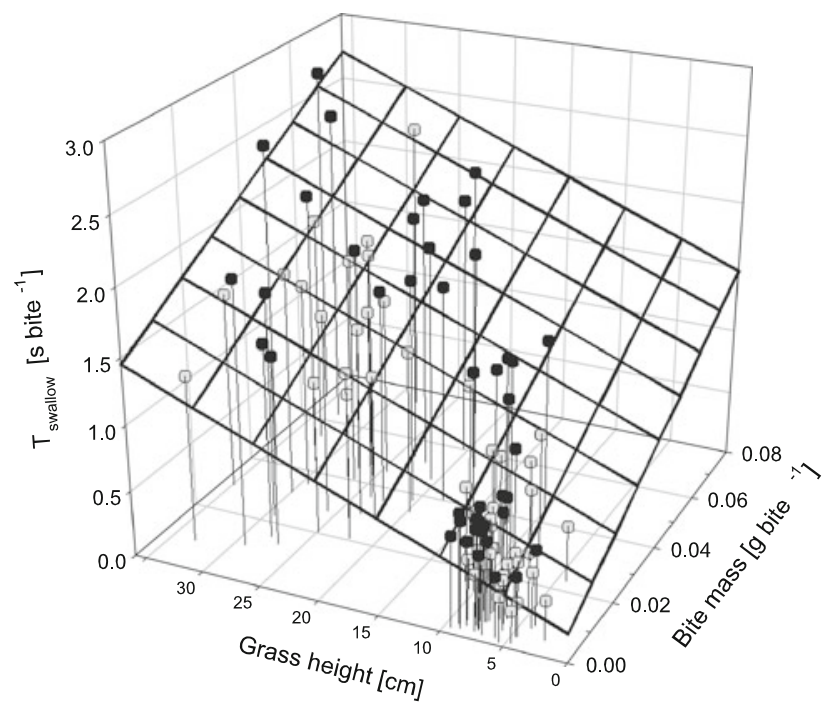

Fig. 4 Influence of the grass height on the relationship between bite mass and swallowing time for the largest body mass class. Regression: $T_{\text {swallow }}=0.21+15.71 \times$ bite mass $+0.034 \times$ grass height, $R^{2}=0.85, F_{2,90}=258.7 .25, P<0.0001$. Open, grey dots indicate observations that lie below the plane, black dots represent observations that lie above the plane

optimum. Both for intake rate and bite mass, the effect of body mass was not linear: the most likely models included a scaling exponent that was slightly smaller than one for intake rate (0.89) and 1.28 for bite mass. Relative to their body mass, the larger geese therefore had larger bites but lower intake rates compared to the smaller geese. Maximum intake rate scaled isometrically with body mass (Heuermann 2007) which is in agreement with the exponent found by Fleurance et al. (2009) for different-sized horses but different from the scaling exponent of 0.7 found by Shipley et al. (1994). The smallest body mass class reached their maximum intake rate at lower biomass compared with the larger ones. At swards with low biomass, instantaneous intake rate did not differ between body mass classes. There was no advantage found for the smallest geese in terms of dry matter intake in this range, but intake per kilogram body mass was higher in the smallest body mass class. We posit that to tease apart the effects of body mass on key parameters such as food intake or energy intake, but perhaps also life-history parameters, ecologists should make more use of intraspecific variation (Kurvers et al. 2009) and not rely too much on interspecific comparisons.

The different grass biomass optima of the three body mass classes and the higher dry matter intake per kilogram of the smallest size class at low biomass swards provide a basis for coexistence of the size classes (Prins and Olff 1998; van Langevelde et al. 2008). This is because the smallest body mass class should be competitively superior at swards with low biomass while the largest body mass class will have an advantage at taller swards due to its lower relative energy requirements combined with an assumed higher digestive efficiency. Although the body mass effects are easiest to show within one species or a group of closely related species, they will also be present in diverse communities as there are indications that even large mammalian grazers show a decrease in their intake rate as a response to complex vegetation (Bergman et al. 2000; Drescher 2003; Benvenutti et al. 2006). In cattle, the decrease in intake rate at tall swards is caused by a reduction in bite mass as well as an increase in handling time. Differences in body mass will lead to differences in optimal food biomass and thereby provide an important mechanism for niche differentiation in grazer communities (Ritchie and Olff 1999).

\section{Functional response}

Intake rate was measured as an average over a period of approximately 2 min while the turf biomass was reduced. Instantaneous intake rate will decrease during this depletion of the turf (Ginnett et al. 1999; Searle et al. 2005), depending on the amount of biomass removed. As the depletion of the turfs was highest for those turfs with a low starting biomass, the measured intake rate was possibly lower than true instantaneous intake rate in those trials, although we found no negative effect of the percentage of biomass removed on intake rate. Even if there was such an effect, this would not change the main conclusion of the analysis, as it only implies that the peak intake rate at low biomass might have been higher than those values we report, and the decrease at higher biomass therefore steeper.

Using the Spalinger and Hobbs process 3 functional response model (Spalinger and Hobbs 1992) showed that bite mass was a better predictor of intake rate than grass biomass. However, this approach has several disadvantages: the model does not provide evidence for or against a type IV functional response, neither can it explain why a decrease in intake rate occurs at high grass biomass while bite mass is constant. Furthermore, under field situations, it is more convenient to predict intake rates from sward measures because bite mass is as difficult to measure as intake rate.

Instantaneous intake rate followed a Type IV functional response with a clear decrease at high biomass for small and large Canada geese. The Type IV functional response model was superior to the Type II model for the majority of our experiments, but for the intermediate-sized geese it was not significantly better. We found that the Monod-Haldane function is a good alternative to the more standard Michaelis-Menten equation in describing the functional 
response of grazing herbivores in relation to grass biomass. The parameter estimates of this function, however, are not so simply related to mechanistic parameters of the foraging process (Gentleman et al. 2003).

Why did intake rate decrease at high biomass?

Either a decrease in bite mass or in bite rate or a decrease in both can lead to a decrease in intake rate. A large fraction of the bite masses measured could be described reasonably well by an asymptotic model, indicating that bite mass increased with sward biomass up to a certain level beyond which it remained constant. The maximum bite volume determined by the dimensions of the grazers' bills was reached at about 36,57 , and $79 \mathrm{~g} \mathrm{~m}^{-2}$, for small, intermediate and large geese, respectively. These biomasses were equivalent to plant heights of 11,15 , and $18 \mathrm{~cm}$, respectively.

While bite mass reached an asymptote at high biomass, the instantaneous intake rate decreased because searching, cropping, and swallowing time further increased as we expected (Fig. 3). An increase in cropping and swallowing time indicated a mechanical explanation for the decrease in bite rate. The time to crop increased with increasing plant height, as expected by Durant et al. (2003), and the number of leaves per plant. This might reflect the higher effort to sever larger bites, which consist of more leaves per bite. Furthermore, these leaves are older and therefore tougher with a higher lignified midrib. The time to gather the material into the bill will increase with increasing amount and leaf length, and the intermingling of leaves and stems might also increase cropping time (Drescher et al. 2006). Swallowing time increased with bite mass and grass height (Fig. 4). Long leaves did not fit into the bill at once, and when more and longer leaves stuck out of the bill, it took longer for the geese to manoeuvre them into the bill. This phenomenon was also observed by Lang and Black (2001) and Durant et al. (2003).

At the same time, searching time per bite also increased at high biomass, as the dense mixture of leaves and stems led to an increase in the time needed to locate the next appropriate bite (cf. van der Wal et al. 1998). The turfs used during the trials contained few dead leaves and consisted purely of the palatable Lolium perenne; we would therefore expect searching time to increase in swards where the accessibility of bites is lower when green leaves are mixed with dead material and non-forage plants. Using leaf biomass instead of total biomass as an independent variable, which is what is actually consumed by the geese, did not result in a better prediction of food intake because the mixture of food and non-food items within the sward determines the foraging time per bite and therefore the intake rate.

We interpret our observations as showing that, for geese, dense vegetation makes it difficult to find appropriate bites and to gather leaves into the bill. At the same time, the leaves become longer and are more difficult to handle. Both cause a decline in intake rates at high biomass, thus leading to a Type IV functional response with a decrease in dry matter intake rate at high biomass even in homogeneous swards with no dead material. Additionally, in a more natural setting, walking speed decreases in tall vegetation (van der Wal et al. 1998) and the density of food plants decreases while the amount of litter and non-food plants in the sward increases. This will lead to an even steeper decline in intake rate at high sward biomass. Above all, the energy intake will decline as plant quality decreases with grass biomass. Although, for herbivores, Type IV functional responses have been found mainly for small Anatidae but not for large species like greylag geese Anser anser and swans Cygnus (Durant et al. 2003; van Gils et al. 2007), we believe that they are common, especially for selective grazers. A reduction of the instantaneous intake rate due to increased handling and searching time is likely the consequence of a more selective foraging strategy and the avoidance of low quality sward components. The Monod-Haldane function should therefore be used more frequently to describe the functional response in grazers as it is able to capture both Type II and Type IV functional responses.

We have confirmed earlier studies that indicate a Type IV functional response in Anatidae (van der Wal et al. 1998; Lang and Black 2001; Durant et al. 2003) not only after nutrient or energy content has been taken into account (Wilmshurst et al. 1999a) but already on the dry matter level. Herbivores, large as well as small, respond to the negative relationship between sward biomass and quality, by either selecting patches of higher quality and thereby sacrificing intake rate or, if no alternative patches are available, reducing their bite mass and bite rate to select smaller, but higher quality bites within the tall swards (Drescher et al. 2006). However, geese do not only show these behavioural responses, their bill size and shape enable them to reach high intake rates at short, low biomass swards, at the cost of an intake rate depression in tall swards, but also allowing them to reach their highest intake where nutrient intake is highest.

Acknowledgments We thank the staff of the experimental farm "De Ossekampen" for their support in taking care for the geese and the staff of "Unifarm" for growing the grass turfs. Earlier versions of this manuscript were improved by the comments of N.T. Hobbs, R. van der Wal and five anonymous reviewers. Elizabeth Tynan corrected the English. Last but not least we are grateful to Geerten Hengeveld for invaluable discussions and suggestions. 
Open Access This article is distributed under the terms of the Creative Commons Attribution Noncommercial License which permits any noncommercial use, distribution, and reproduction in any medium, provided the original author(s) and source are credited.

\section{References}

Andrews JF (1968) A mathematical model for the continuous culture of microorganisms utilizing inhibitory substrates. Biotechnol Bioeng 10:707-723

Banks RC, Cicero C, Dunn JL, Kratter AW, Rasmussen PC, Remsen JV Jr, Rising JD, Stotz DF (2004) Forty-fifth supplement to the American Ornithologists' Union check-list of North American birds. Auk 121:985-995

Bell RHV (1971) A grazing ecosystem in the Serengeti. Sci Am 225:86-93

Benvenutti MA, Gordon IJ, Poppi DP (2006) The effect of the density and physical properties of grass stems on the foraging behaviour and instantaneous intake rate by cattle grazing an artificial reproductive tropical sward. Grass Forage Sci 61:272-281

Bergman CM, Fryxell JM, Gates CC (2000) The effect of tissue complexity and sward height on the functional response of wood bison. Funct Ecol 14:61-69

Black JL, Kenney PA (1984) Factors affecting diet selection by sheep. II. Height and density of pasture. Aust J Agric Res 35:565-578

Bos D, van de Koppel J, Weissing FJ (2004) Dark-bellied Brent geese aggregate to cope with increased levels of primary production. Oikos 107:485-496

Burnham KP, Anderson DR (2002) Model selection and multimodel inference: a practical information-theoretic approach. Springer, New York

Collins M (1988) Composition and fiber digestion in morphological components of an alfalfa timothy sward. Anim Feed Sci Technol 19:135-143

Delgarde R, Peyraud JL, Delaby L, Faverdin P (2000) Vertical distribution of biomass, chemical composition and pepsincellulase digestibility in a perennial ryegrass sward: interaction with month of year, regrowth age and time of day. Anim Feed Sci Technol 84:49-68

Drescher M (2003) Grasping complex matter. PhD thesis, Wageningen University, The Netherlands

Drescher M, Heitkönig IMA, Raats JG, Prins HHT (2006) The role of grass stems as structural foraging deterrents and their effects on the foraging behaviour of cattle. Appl Anim Behav Sci 101:10-26

Durant D, Fritz H, Blais S, Duncan P (2003) The functional response in three species of herbivorous Anatidae: effects of sward height, body mass and bill size. J Anim Ecol 72:220-232

Fleurance G, Fritz H, Duncan P, Gordon IJ, Edouard N, Vial C (2009) Instantaneous intake rate in horses of different body sizes: influence of sward biomass and fibrousness. Appl Anim Behav Sci 117:84-92

Fryxell JM (1991) Forage quality and aggregation by large herbivores. Am Nat 138:478-498

Fryxell JM, Wilmshurst JF, Sinclair ARE (2004) Predictive models of movement by Serengeti grazers. Ecology 85:2429-2435

Gentleman W, Leising A, Frost B, Storm S, Murra J (2003) Functional response for zooplankton feeding on multiple resources: a review of assumptions and biological dynamics. Deep Sea Res II 50:2847-2875

Ginnett TF, Dankosky JA, Deo G, Demment MW (1999) Patch depression in grazers: the roles of biomass distribution and residual stems. Funct Ecol 13:37-44
Gross JE, Hobbs NT, Wunder BA (1993) Independent variables for predicting intake rate of mammalian herbivores: biomass density, plant density, or bite size? Oikos 68:75-81

Heuermann N (2007) Tall swards and small grazers : competition, facilitation and coexistence of different-sized grazers. Ph.D. thesis, Resource Ecology Group, Wageningen University, Wageningen, The Netherlands. Online available at: http://library. wur.nl/wda/dissertations/dis4242.pdf

Holling CS (1959) The components of predation as revealed by a study of small-mammal predation of the European pine sawfly. Can Entomol 91:293-320

Jarman PJ (1974) The social organization of antelope in relation to their ecology. Behaviour 48:215-267

Jeschke JM, Tollrian R (2005) Effects of predator confusion on functional responses. Oikos 111:547-555

Kurvers R, Eijkelenkamp B, van Oers K, van Lith B, van Wieren S, Ydenberg R, Prins H (2009) Personality differences explain leadership in barnacle geese. Anim Behav 78:447-453

Lang A, Black JM (2001) Foraging effciency in barnacle geese Branta leucopsis: a functional response to sward height and an analysis of sources of individual variation. Wildfowl 52:7-20

Mori H, Chant DA (1966) The influence of prey density, relative humidity, and starvation on the predacious behavior of Phytoseiulus persimilis Athias-Henriot (Acarina: Phytoseiidae). Can J Zool 44:483-491

Ombadi A, Südekum KH, Taube F (2001) Dynamics of changes in digestibility and feed intake by sheep of two ryegrass species during primary growth. J Anim Physiol Anim Nutr 85:385-405

Prins HHT, Olff H (1998) Species richness of African grazer assemblages: towards a functional explanation. In: Newberry DM, Prins HHT, Brown ND (eds) Dynamics of tropical communities. Blackwell, London, pp 449-490

Prins HHT, van Langevelde F (eds) (2008) Resource ecology: spatial and temporal dynamics of foraging. Wageningen, The Netherlands

Ritchie ME, Olff H (1999) Spatial scaling laws yield a synthetic theory of biodiversity. Nature 400:557-560

Searle KR, Vandervelde T, Hobbs NT, Shipley LA (2005) Gain functions for large herbivores: tests of alternative models. J Anim Ecol 74:181-189

Shipley LA, Gross JE, Spalinger DE, Hobbs NT, Wunder BA (1994) The scaling of intake rate in mammalian herbivores. Am Nat 143:1055-1082

Solomon ME (1949) The natural control of animal populations. J Anim Ecol 18:1-35

Spalinger DE, Hobbs NT (1992) Mechanisms of foraging in mammalian herbivores: new models of functional response. Am Nat 140:325-348

Sutherland WJ (1996) From individual behaviour to population ecology. Oxford University Press, London

van de Koppel J, Huisman J, van der Wal R, Olff H (1996) Patterns of herbivory along a productivity gradient: an empirical and theoretical investigation. Ecology 77:736-745

van der Wal R, van de Koppel J, Sagel M (1998) On the relation between herbivore foraging effciency and plant standing crop: an experiment with barnacle geese. Oikos 82:123-130

van Gemerden H (1974) Coexistence of organisms competing for the same substrate: an example among the purple sulfur bacteria. Microb Ecol 1:104-119

van Gils JA, Gymesi A, van Lith B (2007) Avian herbivory: an experiment, a field test, and an allometric comparison with mammals. Ecology 88:2926-2935

van Langevelde F, Drescher M, Heitkönig IMA, Prins HHT (2008) Instantaneous intake rate of herbivores as function of forage quality and mass: effects on facilitative and competitive interactions. Ecol Model 213:273-284 
Welty JC (1934) Experiments in group behaviour of fishes. Physiol Zool 7:85-128

Wilmshurst JF, Fryxell JM, Colucci PE (1999a) What constraints daily intake in Thompson gazelles? Ecology 80:2338-2347

Wilmshurst JF, Fryxell JM, Farm BP, Sinclair ARE, Henschel CP (1999b) Spatial distribution of Serengeti wildebeest in relation to resources. Can J Zool 77:1223-1232
Wilson SL, Kerley GIH (2003) Bite diameter selection by thicket browsers: the effect of body size and plant morphology on forage intake and quality. For Ecol Manag 181:51-65 